\title{
Pengaruh Media Sosial dan Eksistensi Bahasa Indonesia di Era Milenial
}

\author{
Fullaikhah Anjani \\ Mahasiswa Program Studi Pendidikan Biologi, Fakultas Keguruan dan Ilmu Pendidikan \\ Universitas Sebelas Maret, Surakarta, Indonesia \\ anjanifullaikhah16@gmail.com
}

\begin{abstract}
Indonesian Language is language unity of Indonesians. In the millennials, application of Indonesian language more and more fade away because Foreign influence in millennials society. The purpose of this research is to describe the mistakes on caption in Instagram and changed vocabulary that's good and true on big dictionary Indonesian Language.Research methods used is with data photo collection from multiple accounts social media on instagram. Millennials have a typycal character is to make the internet a staple in their lives socializing in social media, one of them instagram. The impact of the caption user on instagram is Indonesian Language in the millennial era are fading away.
\end{abstract}

Keywords : The existence of Indonesian Language, social media, Instagram.

\section{Pendahuluan}

Perkembangan di bidang inovasi teknologi informasi dan telekomunikasi atau jejaring lainnya, saat ini merupakan satu bentuk kemajuan teknologi dimana telepon dikembangkan menjadi handphone yang merupakan sistem telepon genggam alat komunikasi elektronik yang ditemukan oleh Martin Coper pada tahun 1973 ( Saputra,dkk,2018).

Di era milenial ini, media sosial bersifat interaktif dengan fungsi spesisifik dan berevolusi sangat cepat tanpa adanya kendali yang memungkinkan pengguna dan masyarakat individual untuk berbagi, saling menciptakan,mendiskusikan dan memodifikasi konten yang dihasilkan. Jurnal internasional ( Muninger et al,2018)

Instagram adalah media sosial berbasis video-video, yang berisi tulisan dan berbasis teks dengan tagar dan komentar. Instagram adalah salah satu media sosial pertama yang memiliki akun selebriti dan menjadi populer di kalangan politisi( Gruzd et al,2018)

Bahasa adalah sistem lambang suara ucapan yang dihasilkan oleh alat ucap manusia. Bahasa juga digunakan manusia sebagai alat komunikasi untuk berinteraksi diantara manusia. Selain itu bahasa memengaruhi kepada kehidupan sosial, budaya, perekonomian, bahkan kehidupan agama, dan adanya susatu bahasa berarti adanya media komunikasi yang dapat menghasilkan suatu informasi-informasi berbagai hal. Bahasa dapat dipengaruhi oleh keadaan geografis, keadaan lingkungan, iklim, dan kebudayaan yang berbeda menimbulkan keanekaragaman yang berbeda (Nugraha,2015)

Seiring dengan perkembangan zaman, bahasa Indonesia mengalami perkembangan, baik ke arah positif maupun negatif. Keadaan yang ada sekarang adalah fungsi bahasa Indonesia mulai digantikan atau tergeser oleh bahasa asing dan adanya perilaku yang cenderung menyelipkan istilah asing, padahal padanan dalam bahasa Indonesianya ada, dikarenakan sikap yang meyakini bahwa akan terlihat modern, dan terpelajar jika menggunakan istilah atau bahasa asing dalam 
berkomunikasi pada pergaulan sehari-hari. Hal tersebut berdampak pada eksistensi bahasa Indonesia. 'Eksistensi' dapat diartikan keberadaaan. Dalam hal ini yang dimaksud adalah keberadaan bahasa Indonesia, yang salah satunya dapat dilihat dari pengetahuan tentang kosakatakosakata dalam bahasa Indonesia (Putri,2017)

Bahasa gaul adalah gaya bahasa yang merupakan perkembangan atau modifikasi dari berbagai macam bahasa, termasuk bahasa Indonesia,sehingga bahasa gaul tidak memiliki sebuah struktur gaya bahasa yang pasti. Sebagian besar kata-kata dalam bahasa gaul remaja merupakan terjemahan,singkatan, maupun pelesetan. Namun, terkadang diciptakan pula kata-kata aneh yang sulit dilacak asal mulanya (Nurhasanah,2014:15).

Menurut A.D. Friman bahasa gaul Indonesia sebenarnya sudah ada sejak 1970-an awalnya istilah-istilah dalam bahasa gaul bertujuan untuk merahasiakan isi obrolan dalam komunitas tertentu. Namun, karena sering juga digunakan di luar komunikasinya lama kelamaan istilah-istilah tersebut menjadi bahasa sehari-hari (Swandy,2017)

Dialek Ngapak yaitu dialek bahasa Jawa yang dituturkan di wilayah eks karesidenan Banyumas, Tegal dan Brebes ( Khotimah,2017).

Penggunaan bahasa Indonesia yang baik dan benar sangat penting untuk diketahui oleh para remaja. Hal ini supaya bahasa Indonesia yang merupakan bahasa nasional, bahasa persatuan, dan bahasa pengantar dalam dunia pendidikan bisa tetap ada dan tidak kalah eksistensinya oleh bahasa gaul. Penggunaan bahasa gaul yang semakin banyak dikalangan remaja membuat eksistensi bahasa Indonesia menjadi menurun. Oleh karena itu, pengaruh bahasa gaul terhadap penggunaan bahasa Indonesia yang baik dan benar di kalangan remaja harus mendapat perhatian (Gustiasari,2018).

\section{Metode}

Penelitian ini menggunakan metode deskriptif kualitatif dengan pendekatan analisis isi. Secara kualitatif artinya data yang diteliti dan hasil analisisnya diperoleh dari rekaman, pengamatan, wawancara, atau bahan tertulis, dan data ini tidak berbentuk angka. Sementara itu, pendekatan deskriptif mendasarkan pada fakta, yang secara empiris diperoleh dari penutur-penuturnya, sehingga hasilnya berupa perian bahasa seperti apa adanya (Zein dan Wagiati, 2018) Disamping itu ,dilakukan wawancara terhadap pemilik atau admin akun @cilacap_kekinian dengan tujuan mengetahui latar belakang pembuatan akun tersebut.Teknik yang digunakan dalam penelitian ini yaitu dengan cara tangkap layar foto-foto yang akan dijadikan sampel.

\section{Pembahasan}

Akun instagram @cilacap_kekinian merupakan suatu akun instagram daerah yang berasal dari Cilacap, Provinsi Jawa Tengah. Awalnya akun ini bernama @igerscilacap yang di buat pada tanggal 3 Oktober 2015. Nama pemilik akun @ igerscilacap yaitu Mas Yazid Afifudin Abror yang berasal dari Kecamatan Kroya, Kabupaten Cilacap. Menurut Mas Yazid, latar belakang pembuatan akun ini berawal dari keinginannya untuk membuat sebuah komunitas pengguna instagram di daerah Cilacap. Seiring berjalannya waktu, akhirnya admin mengganti nama @igerscilacap menjadi @cilacap_kekinian. Pergantian nama @igerscilacap menjadi @cilacap_kekinian yaitu sekitar awal bulan desember 2018. Akun @ cilacap_kekinian dilihat dari unggahannya terdiri dari foto dan video yang berkaitan dengan daerah Cilacap, baik dalam hal wisata kuliner, tempat wisata baru dan info terkini seputar daerah Cilacap. Akun ini memiliki pengikut sebanyak 21,6 ribu dengan jumlah unggahan sebanyak 1160 . Dalam akun instagram ini bahasa yang digunakan dalam keterangan foto menggunakan bahasa Indonesia yang dipadukan dengan bahasa Banyumasan(dialek Ngapak), bahasa gaul dan bahasa Inggris. Disamping itu, dipilih juga salah satu akun yang akan menjadi pembanding dari akun@cilacap_kekinian yaitu akun @komiknyebelin dengan pengikut sejumlah 105 ribu dengan unggahan sebanyak 35. Foto yang diunggah oleh @komiknyebelin juga menggunakan bahasa Indonesia yang dipadukan dengan bahasa gaul atau kekinian ,selain dilihat dari konteks bahasa, keterangan dalam foto unggahan bersifat ekspresif dan juga dilengkapi dengan gambar yang menarik. 


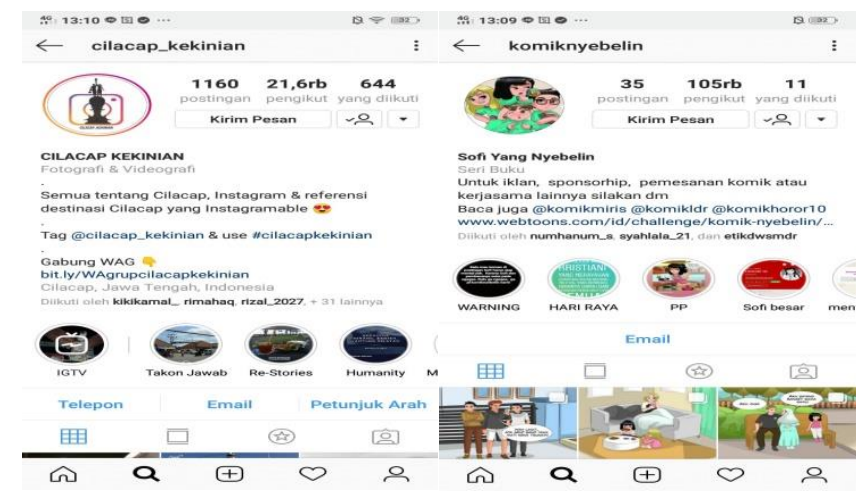

Ejaan Bahasa Indonesia (EBI) adalah tata bahasa dalam Bahasa Indonesia yang mengatur penggunaan bahasa Indonesia dalam tulisan,mulai dari pemakaian huruf, penulisan kata, penulisan unsur serapan , serta penggunaan tanda baca. PUEBI juga dapat diartikan sebagai suatu ketentuan dasar menyeluruh yang berisi acuan penggunaan bahasa Indonesia secara baik dan benar.

Data hasil penelitian

\section{Penulisan Kata}

\section{Data (1)}

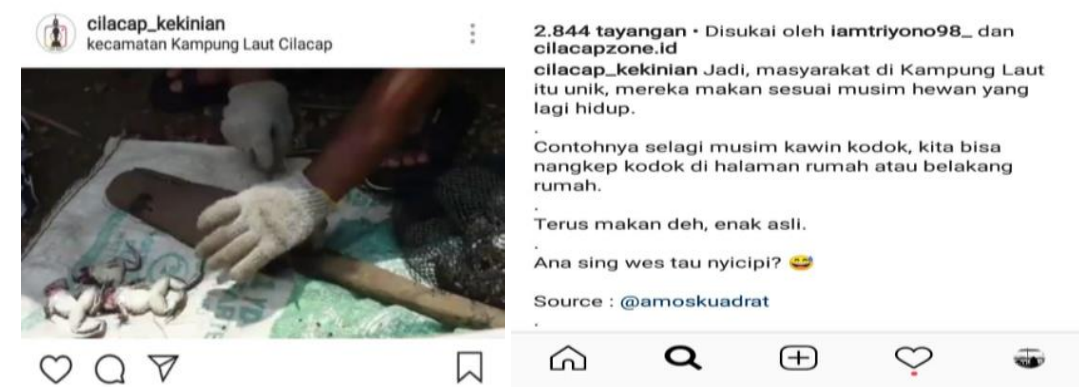

Keterangan pada foto yang diunggah pada data 1

Jadi,masyarakat di Kampung Laut itu unik, mereka makan sesuai musim hewan yang lagi hidup.

Contohnya selagi musim kawin kodok, kita bisa nangkep kodok di halaman rumah atau belakang rumah.

Terus makan deh,enak asli.

Ana sing wes tau nyicipi?

Pada keterangan foto yang di unggah oleh @cilacap_kekinian pada tanggal 30 November 2018, terdapat penulisan kata- kata yang tidak sesuai dengan kaidah bahasa Indonesia yang baik dan benar serta terdapat kalimat yang menggunakan kata-kata dalam bahasa Jawa.

\begin{tabular}{|l|l|}
\multicolumn{2}{|c|}{ Tabel Data 1 } \\
\begin{tabular}{|l|l|} 
Kata \\
dalam \\
Bahasa \\
Jawa
\end{tabular} & $\begin{array}{l}\text { Penulisan } \\
\text { benar } \\
\text { PUEBI } \quad \text { yang }\end{array}$ \\
\hline Nangkep & Menangkap \\
\hline Ana & Ada \\
\hline Sing & Yang \\
\hline Wes & Udah \\
\hline Tau & Pernah \\
\hline Nyicipi & Mencicipi \\
\hline
\end{tabular}


Ditinjau dari keefektifan kalimat, keterangan tersebut masih belum efektif. Perbaikan kalimat efektif sesuai kaidah bahasa Indonesia yang baik dan benar yaitu:

Masyarakat di Kampung Laut memiliki kebiasaan yang unik, terutama saat musim kawin kodok. Mereka dapat menangkap kodok di halaman atau belakang rumah. Kodok tersebut kemudian di masak sebelum dikonsumsi. Apakah sudah ada yang pernah mencicipinya?

Data (2)

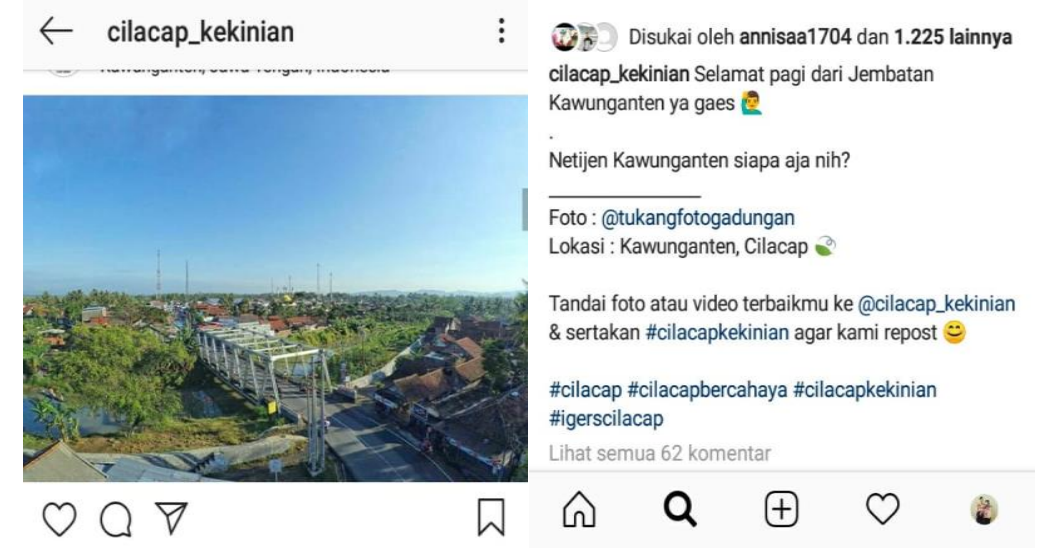

Keterangan pada foto yang diunggah pada data 2

Selamat pagi dari Jembatan Kawunganten ya gaes

Netijen Kawunganten siapa aja nih?

Pada keterangan foto yang di unggah oleh @ cilacap_kekinian pada hari tanggal 12 Desember 2018, terdapat kata-kata dalam bahasa gaul dan bahasa asing.

\begin{tabular}{|l|l|}
\hline Bahasa & Arti dalam \\
Gaul & Indonesia \\
\hline Gaes & Teman \\
\hline
\end{tabular}

\begin{tabular}{|c|c|c|}
\hline $\begin{array}{l}\text { Penulisan } \\
\text { Kata }\end{array}$ & $\begin{array}{l}\text { Yang } \\
\text { Benar }\end{array}$ & $\begin{array}{l}\text { Kosakata } \\
\text { dalam } \\
\text { Bahasa } \\
\text { Indonesia }\end{array}$ \\
\hline Netijen & Netizen & Warganet \\
\hline
\end{tabular}

Ditinjau dari keefektifan kalimat, keterangan tersebut masih belum efektif. Perbaikan kalimat efektif sesuai kaidah bahasa Indonesia yang baik dan benar yaitu:

Selamat pagi.

Siapa saja warganet Kecamatan Kawunganten?

Penghilangan kata Jembatan Kawunganten dalam kalimat diatas menurut saya kurang tepat karena biasanya ucapan seperti selamat pagi, selamat siang dan sebagainya diikuti dengan kata sapaan misalnya Pak atau Bu bukan diikuti keterangan tempat.

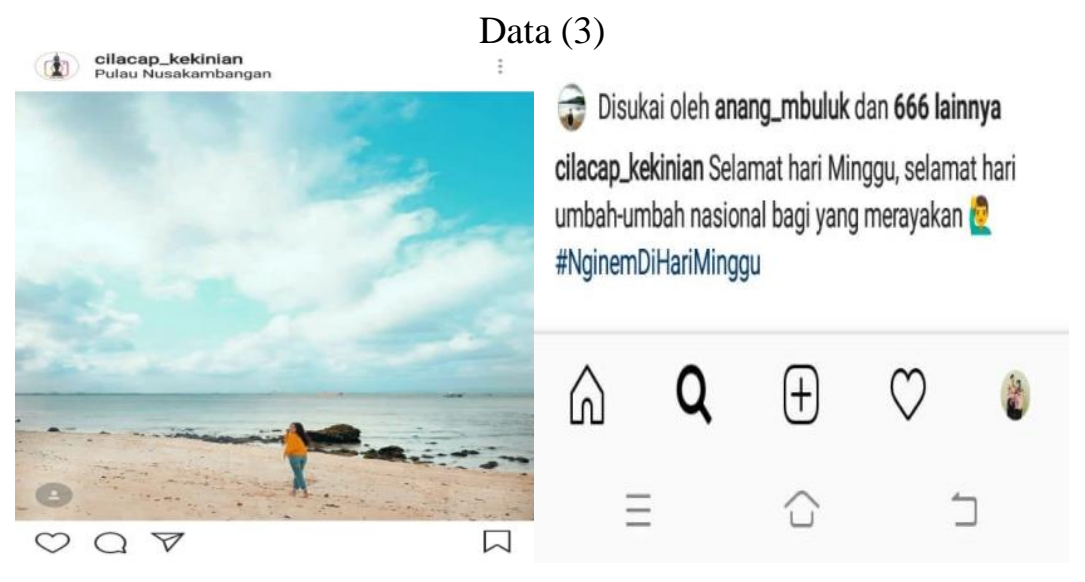


Keterangan pada foto yang diunggah pada data 3

Selamat hari Minggu, selamat hari umbah-umbah nasional bagi yang merayakan

Pada keterangan foto yang di unggah @ cilacap_kekinian pada tanggal 25 November 2018, terdapat kata-kata dalam Bahasa Jawa yaitu:

\begin{tabular}{|l|ll|}
\hline $\begin{array}{l}\text { Kata dalam } \\
\text { Bahasa Jawa }\end{array}$ & $\begin{array}{l}\text { Arti dalam } \\
\text { Indonesia }\end{array}$ & Bahasa \\
\hline $\begin{array}{l}\text { Umbah- } \\
\text { umbah }\end{array}$ & Mencuci & \\
\hline
\end{tabular}

Ditinjau dari keefektifan kalimat, keterangan tersebut masih belum efektif. Perbaikan kalimat efektif sesuai kaidah bahasa Indonesia yang baik dan benar yaitu:

Selamat hari Minggu dan selamat beraktivitas.

Penghilangan kata umbah-umbah dalam kalimat tersebut dikarenakan tidak keefektifan pada kalimat dan tidak sesuai dengan suasana yang tergambar di foto tersebut.

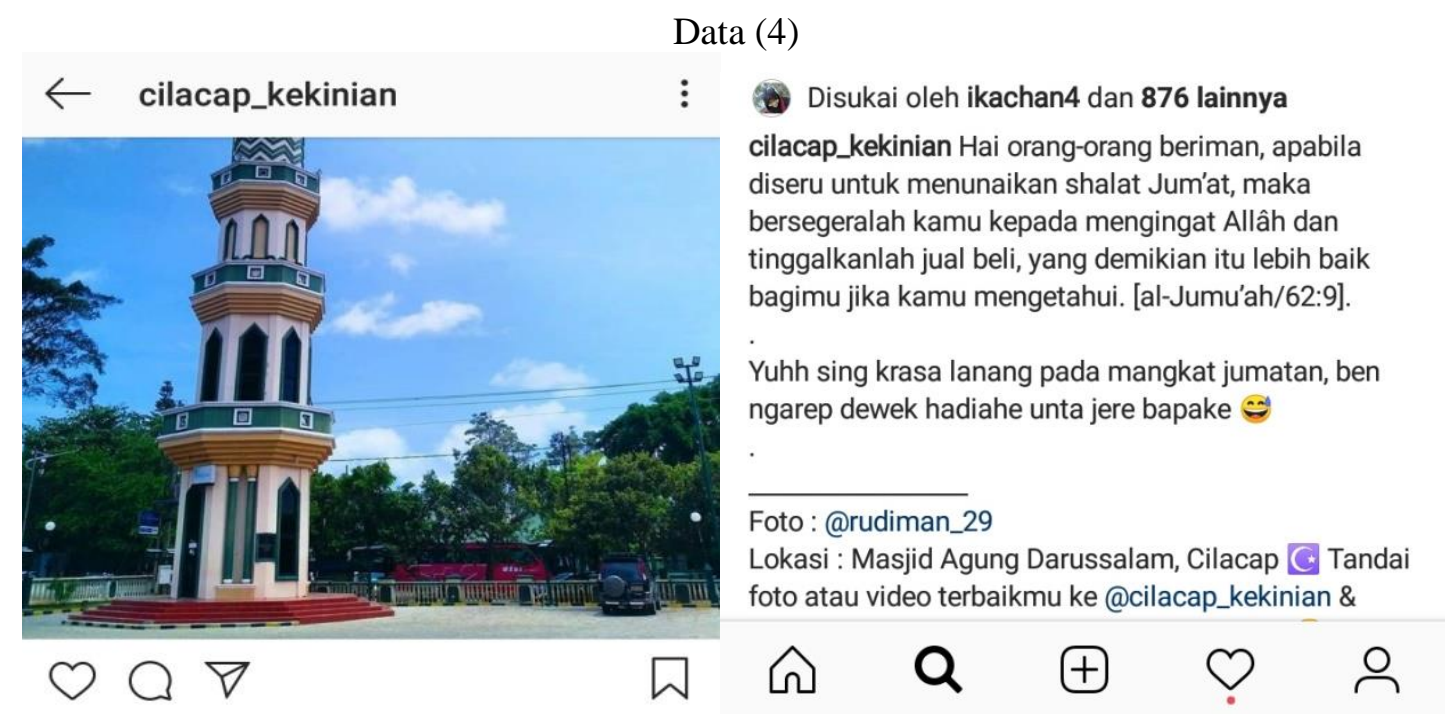

Keterangan foto pada data 5

Hai orang-orang beriman,apabila diseru untuk menunaikan shalat Jum'at, maka bersegeralah kamu kepada mengingat Allah dan tinggalkanlah jual beli, yang demikian itu lebih baik bagimu jika kamu mengetahui. [ al-Jumu'ah/62:9].

Yuhh sing krasa lanang pada mangkat jumatan, ben ngarep dewek hadiahe unta jere bapake.

Pada keterangan foto yang di unggah @ cilacap_kekinian pada tanggal 12 November 2018 , terdapat penulisan yang tidak sesuai dengan Kamus Besar Bahasa Indonesia dan terdapat singkatan-singkatan yang tidak sesuai PUEBI.

\begin{tabular}{|l|l|}
\hline Penulisan Kata & $\begin{array}{l}\text { Penulisan yang benar } \\
\text { sesuai PUEBI }\end{array}$ \\
\hline Shalat & Salat \\
\hline Jum'at & Jumat \\
\hline
\end{tabular}

Ditinjau dari segi bahasa yang digunakan pada keterangan foto yang diunggah terdapat kata-kata dalam bahasa dialek Banyumasan atau Ngapak yang dipadukan dengan bahasa Indonesia dan konteks kalimat tersebut tidak sesuai dengan penggunaan bahasa Indonesia yang baik dan benar.

Ditinjau dari keefektifan kalimat, keterangan tersebut masih belum efektif. Perbaikan kalimat efektif sesuai kaidah bahasa Indonesia yang baik dan benar yaitu: 
Hai orang-orang beriman, apabila diseru untuk menunaikan salat Jumat, maka bersegeralah kamu kepada mengingat Allah dan tinggalkanlah jual beli, yang demikian itu lebih baik bagimu jika kamu mengetahui [ al-Jumu'ah/62:9]

Penghilangan kalimat "Yuhh sing krasa lanang pada mangkat jumatan, ben ngarep dewek hadiahe unta jere bapake" dikarenakan kalimat ini merupakan kalimat ajakan akan tetapi jika diterjemahkan ke dalam bahasa Indonesia seluruhnya ,konteks kalimatnya menjadi tidak sesuai.

Terjemahan kalimat tersebut ke dalam bahasa Indonesia yaitu ayo yang merasa lelaki pada berangkat Jumatan, biar depan sendiri hadiahnya unta kata Bapaknya.

Berdasarkan data yang diperoleh mengenai penulisan kata yang terdapat pada akun instagram @ cilacap_kekinian, terdapat beberapa kesalahan penulisan yang tidak sesuai dengan Pedoman Umum Ejaan Bahasa Indonesia (PUEBI). Ditinjau dari penulisan kata, kata yang digunakan pada keterangan foto termasuk bahasa gaul dan bahasa Ngapak. Penggunaan kata-kata dalam bahasa Jawa seperti nangkep,ana,sing,wes,tau,nyicipi, dan umbah-umbah tidak ada dalam Kamus Besar Bahasa Indonesia. Akan tetapi, tujuan dari pembuatan akun ini, menggunggah foto-foto dengan keterangan menggunakan bahasa Indonesia yang dipadukan dengan bahasa gaul, bahasa Jawa dialek Ngapak dan beberapa kata dalam bahasa Inggris sebenarnya agar pembaca tidak bosan dengan keteranganketerangan foto dengan satu bahasa. Dilihat dari penggunaan bahasa yang digunakan dalam keterangan foto-foto yang diunggah juga lebih banyak menggunakan bahasa dialek Ngapak karena tujuan admin yang berkeinginan untuk memperkenalkan bahasa daerah Cilacap yaitu bahasa dialek Ngapak.

\section{Kesimpulan}

Penggunaan bahasa dalam media sosial khususnya instagram di era milenial ini memengaruhi eksistensi bahasa Indonesia. Penggunaan bahasa Indonesia yang baik dan benar dalam penggunaannya semakin memudar dikalangan generasi millenial. Padahal generasi milenial diharapkan dapat menjadi generasi yang dapat mempertahankan bahasa Indonesia sebagai bahasa nasional dan bahasa persatuan Indonesia. Berdasarkan salah satu akun instagram yang dipilih, terdapat beberapa penulisan kalimat yang tidak sesuai dengan penggunaan bahasa Indonesia yang baik dan benar. Akan tetapi, menurut hasil wawancara pada pemilik akun @cilacap_kekinian, bahasa yang digunakan yaitu merupakan keinginan admin untuk memperkenalkan dan mengembangkan bahasa dialek Ngapak agar tidak pudar di era milenial

\section{DAFTAR PUSTAKA}

Gustiasari,D.(2018).Pengaruh Perkembangan Zaman Terhadap Pergeseran Tata Bahasa Indonesia Studi Kasus Pada Pengguna Instagram Tahun 2018.Jurnal Renaissance.Vol.3No(2)

Gruzd et al.(2018). Examining Goverment Cross-Platform Engagement In Social Media: Instagram Vs Twitter And The Big Lift Project. Goverment Information Quarterly.Vol.3(1)

Khotimah,Siti.(2017).Konstruksi Identitas Kultural "Wong Ngapak”Melalui Konsumsi Media Lokal Dialek Banyumasan.SBN Studi Budaya Nusantara.Vol 1 No.(2)

Nugraha.(2015).Pengaruh Kontak Bahasa Masyarakat Desa Majalaya dengan Pendatang dan Peziarah Terhadap Campur Kode.Jurnal Semantik,55-70

Muninger et al.(2018).The value of social media for innovation: A capability perspektive.Journal Of Business Reseach 95. pp 116-127

Nurhasanah,Nina.(2014).Pengaruh Bahasa Gaul Terhadap Bahasa Indonesia:Forum Ilmiah Vol 11 Nomer 1 Januari 2014,(Online). (http://ejournal.undip.ac.id/index.php/Formil/article/viewFile/863/793,diaksees pada tanggal 29 Desember 2018

Putri,N.(2017).Eksistensi Bahasa Indonesia Pada Generasi Millennial.Widyabastra. Vol.05, No(1) Saputra,D., Arsyad, Upe,A.(2018).Potret Sosial Remaja Masa Kini.Neo Societal.vol.3,No(3) Swandy,E.(2017).Bahasa Gaul Remaja Dalam Media Sosial Facebook.Jurnal Bastra.Vol.1,No(4) Zein,D dan Wagiati.(2018).Bahasa Gaul Kaum Muda Sebagai Kreativitas Linguistis Penuturnya Pada Media Sosial Di Era Teknologi Komunikasi Dan Informasi. Jurnal Sosioteknologi. $\operatorname{Vol} .7, \mathrm{No}(2)$. 